\title{
Infographic Modeling of Reorganization of Digitalized Cyber-Physical Systems Throughout the Life Cycle of Construction Projects
}

\author{
Vitaliy O. Chulkov* \\ Department of Technology and Organization of Building Production, National Research University «Moscow State \\ University of Civil Engineering», Moscow, Russia. \\ *Corresponding author. Email: vitolch@gmail.com
}

\begin{abstract}
In the near future, digitalized cyber-physical systems must become the basis of the processes and means of computer control of a variety of functioning parameters of a modern home, as well as instrumental monitoring of the dynamics of their change within specified limits. This goal was set by the Government of the Russian Federation, bearing in mind the need to significantly increase the volume and quality of health of the population, to ensure the necessary level of comfort for the functioning of people in their life and work. To ensure the achievement of this goal, it is necessary to have a clear idea of the current state of the problem in question, to simulate the possibility of its dynamic change at the scheduled time. Infographic models of anthropotechnics for managing the reorganization of construction projects throughout their life cycle, their physical engineering systems of high-tech service and computer systems of digital economy are proposed. A comprehensive combination of the capabilities of these components within the framework of digitalized cyber-physical construction systems allows us to hope for a timely and high-quality solution to the goal set by the country's leadership. There are no outdated digital monitoring and control platforms in Russia, unlike the foreign practice of digitalization. There is an opportunity to quickly and fully integrate new original domestic pilot-projects. An example of the possibility of introducing digitalization technologies for monitoring and control can be the control of changes in the adaptive norms of a particular person in a dynamically changing environment. The domestic and foreign practice of research in this field can be effectively combined with a currently actively developing study of cyber-physical systems and digitalization of their management.
\end{abstract}

Keywords: digital management, multilayer infographic models, digital economy, cyber-physical systems,

anthropotechnical management, computer monitoring

\section{INTRODUCTION}

The pinnacle of modern development of cybernetics is the concept of cyberspace and cyber system, in particular, the cyber-physical system (CPS). Digitalized [1,2, etc.] cyberphysical systems [3-8 and others] are designed to comprehensively combine the capabilities of cybernetics (science and practice of managing and transmitting information in biological, technical, public and other systems [9-18 etc.]), high-tech physical engineering service systems $[19,20$, etc.] and digital economy systems. [21-25 and others]. At different times, the applied science of 'informatics' (as a narrow field of cybernetics [26]), 'cyberspace' and 'digital space' (as virtual reality in computer technology, 1984-1988 [27, etc.]), 'model engineering' and infographic modeling were explained [28, 29 and others]. The electronic economy is distinguished from the traditional one by its significant dependence on the Internet of things [30], virtuality and the multilayer digital control [31] built into it, using telecommunication networks and computer equipment. Cyber-physical systems in construction are classified [32 and others] as applied cybernetics; they imply the study of natural phenomena and technical processes from the standpoint of the needs and limitations of a functioning person (a designer, a builder or a user of the building).

\section{RESEARCH METHODOLOGY}

The systemic, comparative and qualitative analysis, infographic modeling and anthropotechnical management were chosen as the basis of the study.

\section{RESEARCH RESULTS}

Modern ideas record several interconnected levels of perception and comprehension, recognizing the feasibility of using a multilayer infographic model of activity formation (Fig. 1, 2 [34]). Fig. 1 shows a basic model of one layer of this 
model (which is usually called 'a stack' by methodologists), and Fig. 2 describes the principle of logical "assemblingdisassembling” of such a multilayer model.

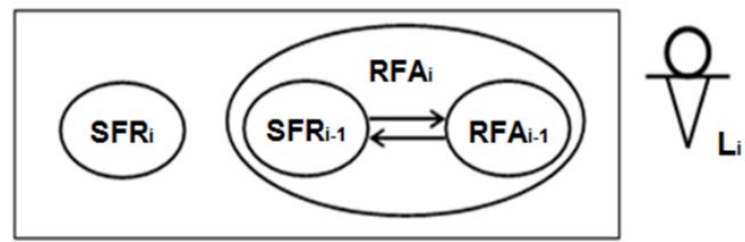

Figure 1 The model of one layer of 'the stack' (Chulkov V.O., [34])

Explanation of symbols

$\mathbf{S F R}_{\mathbf{i}}$ - a system-forming resource of the i-th layer of the 'stack', which provides conversion of a double set of the i-th

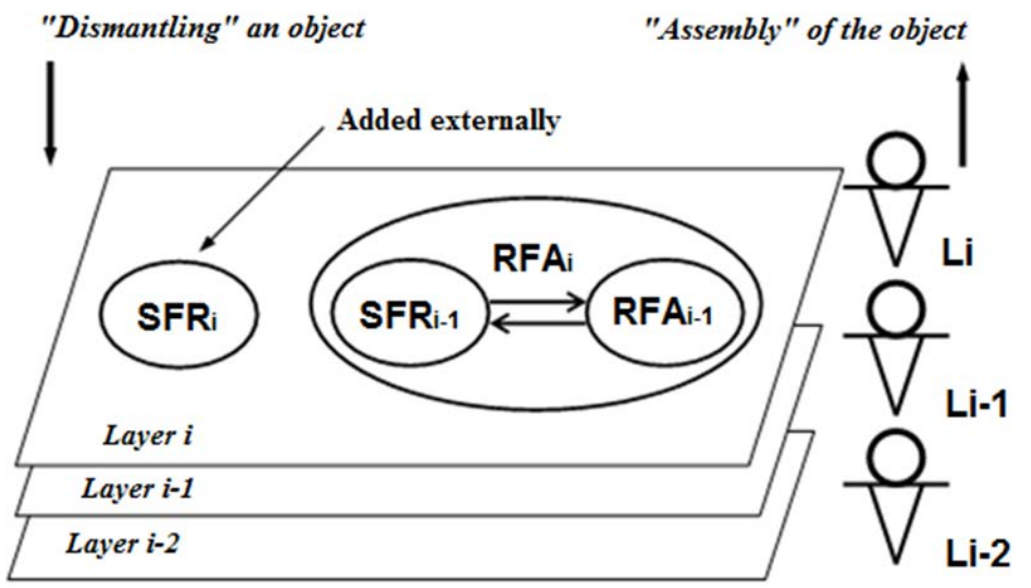

Figure 2 A fragment of a multilayer infographic model of activity formation (Chulkov V.O., [34])

The right component of $\mathbf{R F A _ { i }}$ is a copy of the double set of the plane of $\mathbf{i}-1$ level (the result of functional activity of $Д_{\mathbf{i}}$ in $\mathbf{i}-1$ layer). $\mathbf{R}_{\mathbf{n}}$ function of the transfer of RFA from $n-1$ plane to $n$ plane:

$\mathbf{R}_{\mathbf{n}}=\mathbf{F}\left\{\mathbf{S F R}_{\mathbf{i}} \leftrightarrow \mathbf{R F A}_{\mathrm{i}-1}\right\}=\left\{\mathbf{S F R}_{\mathbf{i}} \leftrightarrow\left(\mathrm{SFR}_{\mathbf{i}-1} \leftrightarrow \mathbf{R F A}_{\mathrm{i}-2}\right) \boldsymbol{\}}\right.$ Such transfer is performed by the agent who is responsible for layer $\mathbf{i}$ of the stack, realizing in it the functional activity displayed by this layer, and who is the main manager of the functional activity system implemented in this layer.

A fragment of the 'stack' (Fig. 2) can be continued in the direction of 'assembling' (from parts to the whole) or in the direction of 'disassembling' (from the whole to parts). The position of agent $Д_{\mathbf{i}}$ should be formalized to control the quality of the activity and its results. Not all activity positions marked with a human figure near the corresponding plane of the 'stack' are constantly occupied by actual actuators. In certain cases, the same person can alternately work in several activity positions. It is important that in each of the positions the person clearly understands and performs all his functions.

The transfer of RFA is carried out between adjacent layers (Fig. 3). layer into a workable functional activity system and the transfer of this system to the $\mathrm{i}+1$ layer; $\mathbf{R F} \mathbf{A}_{\mathbf{i}}$ - the result of functional activity; $Д_{\mathbf{i}}$ - an agent responsible for layer $\mathrm{i}$ of 'the stack'.

When moving along the 'stack' from bottom to top, 'assembling' takes place (blocking, increasing the scale and significance of the activity under study), and when moving along the 'stack' from top to bottom, a sequential 'disassembling' takes place (downsizing and detailing of the activity under study). The basic model of the 'stack' layer (Fig. 1 ) is a double set (subject and object of the functional system of activity). The left component of $\mathbf{S F R}_{\mathbf{i}}$ (the system-forming resource of the i-th layer of the 'stack' in Fig. 1) transforms the double set of the i-th layer of the 'stack' into a functional activity system and transfers this system to the $\mathbf{i}+\mathbf{1}$ layer of the model. 


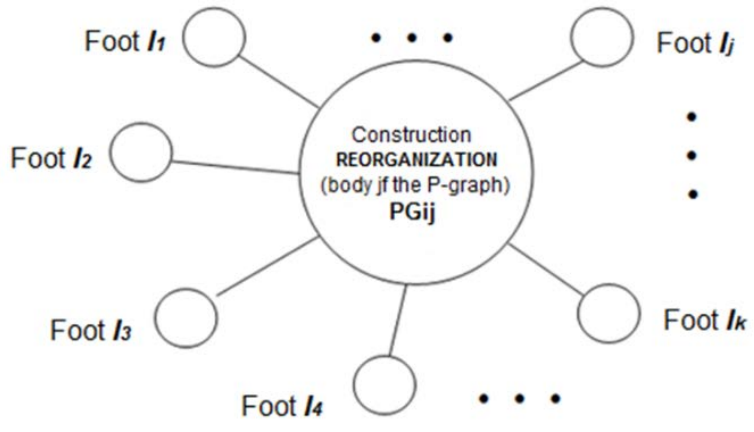

Figure 4 The infographic model of the 'spider-graph', showing the interconnection of innovative types of construction reorganization (Chulkov V.O., 2014)

The algebra of this formal model is different from Codd's relational algebra [38] and allows one to subject both network and relational models to comparative analysis. Among many interconnected points ('elements' or innovative types of construction reorganization) of such a model, the pluralities united by a common relationship with one of the known points (which is called 'the body of the spider-graph', in our case it is renovation) are distinguished. The lines connecting this 'body' with all interconnected elements of the set are called 'legs of the spider-graph' (S-graph). S-graphs can be linked to each other by legs having the same marks.

Such idea of S-graphs' formation is consistent with the totality of multipoint logics, united around one basic concept (singlepoint logic). An information field of the set of elements of different logics is defined by a network of linked S-graphs and denoted by the triad $(\mathrm{S}, \mathrm{L}, \mathbf{N})=,\left\{\mathrm{S}_{\mathrm{t}}\right\}_{\mathrm{t}}=\left\{\left\langle\mathrm{S}_{\mathrm{t}},\left\{<\mathrm{l}_{\mathrm{tk}}, \mathrm{N}_{\mathrm{tk}}\right\rangle_{\mathrm{tk}}\right.\right.$ \}$\left._{\mathbf{k}}>\right\}_{\mathbf{t}}$, where: $S=\left\{s_{t}\right\}_{t}$ is the set of names of the linked Sgraphs; $\mathbf{L}=\left\{\left\{\mathbf{l}_{\mathbf{t k}}\right\}_{\mathbf{k}}\right\}_{\mathbf{t}}$ is the set of all legs of the linked Sgraphs; $N=\left\{\left\{N_{\mathrm{tk}}\right\}_{\mathbf{k}}\right\}_{\mathbf{t}}$ is the totality of marks marking these legs [36].

\section{CONCLUSIONS}

1. The most interesting are management situations where one or more logic points (Fig. 4) are priority. It is necessary to rank and bring into correspondence such priorities, to establish the content and strength of communication of priority and nonpriority points.

2. As an example, Fig. 5 shows a three-dimensional spatial model for determining the relationship of triads with the dominant role of one of the basic concepts. The number of priority points varies from 1 to $\mathbf{m}$ (where $\mathbf{m}$ is the dimension of multipoint logic). The number of models of the whole gamut of possible variants of priority points in the logic equals $\mathbf{m}+1$. 

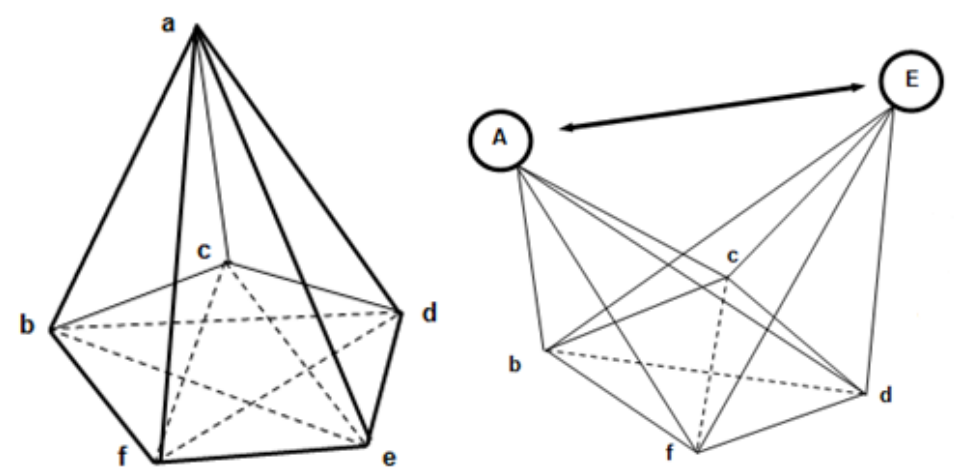

Figure 5 Spatial models of the relationship of triads (three points) with the dominant role of one of the basic concepts (left model) or with the dominant role of one of the dyads (right model) (Chulkov V.O., 2003)

The left model (Fig. 5) reveals connection of the triads with the leading role of one of the six basic concepts (a, b, c, d, e, f), in our case, this concept is a (labor resources and technologies). The right model (Fig. 5) reveals connection of the triads with the dominant role of two basic concepts (dyad A-E).

3. This series of models have the property of symmetry (the use of 'inverse', 'inverted' models). The boundary of occurrence of symmetric (inverted) models of multipoint logics is determined by the following expressions: for logics that have even values $m: \boldsymbol{m} / \mathbf{2}+\mathbf{1}$; for logics that have odd values $m: \boldsymbol{m} / 2$ [39].

\section{REFERENCES}

[1] National Digitalization [Electronic Resource]. https:// rostec.ru/ analytics/natsionalnayatsifrovizatsiya/ (reference date: 10.08.2019).

[2] Khalin V.G., Chernova G.V. Digitalization and its Impact on the Russian Economy and Society: Advantages, Challenges, Threats and Risks, Management Consulting, No, 10, 2018, pp. 46-63.

[3] Cyber-physical system. -

https://ru.wikipedia.org/wiki/ Cyber-physical system (reference date: 6.05.2019).

[4] Sanfelice R.G., (2016) Analysis and Design of Cyber-Physical Systems. A Hybrid Control Systems Approach, Cyber-Physical Systems: From Theory to Practice, D. Rawat, J. Rodrigues, I. Stojmenovic.- CRC Press, 2016.- ISBN 978-1-4822-6333-6.

[5] Lee E.A. (2015) The Past, Present and Future of Cyber-Physical Systems: A Focus on Model Cheng AMK, ed., Sensors (Basel). Vol. 15(3), March, 2015, 4837-4869.

[6] Chernyak L. Cyber-physical Systems at the Start, Open Systems. DBMS.- 2014.- No. 2.- pp.10-15. URL: https://www.osp.ru/os/2014/02/ 13040038 (reference date: 05/06/2019).

[7] Tsvetkov V.Ya. Cyber-physical Systems,
International Journal of Applied and Fundamental Research, 2017, No. 6-1, pp. 64-65; URL: https://applied-research.ru/ru/article/view?id=11623 (reference date: 29.09.2019).

[8] Yastreb N.A. Industry 4.0: cyber-physical systems, intelligent environment, Internet of things. https://techno.vogu35.ru/docs/2015/Industria_4_0_Yast reb.pdf (reference date: 29.09.2019).

[9] Berg A.I. Main Issues of Cybernetics, History of Computer Science in Russia: Scientists and their Schools, Compiling editors: V.N. Zakharov, R.I. Podlovchenko, Ya.I. Fet.- M .: Nauka. - 2003.

[10] Bogdanov A.A. Tectology. General Organizational Science, In 2 volumes, M.: 'Economics', 1989, Volume 1 - 304 p., Volume 2 - 351p.

[11] Bertalanffy L. von. General System Theory, General Systems.- Vol.I.- 1956.- P.1-10.

[12] Sudakov K.V. Functional Systems, M.: RAMS Publishing House, 2011.- 320 p.

[13] Von Neumann, J. Theory of Self-Reproducing Automata, Transl. from English. - M.: 'Mir' Publishing House, 1971. - 384 p.

[14] Von Neumann, J. Computing Machine and the Brain,Cybernetic collection, No. 1, M.: Foreign Literature, 1960,pp.11-60 (manuscript of 1955-56).

[15] Wiener N. Cybernetics or Control and Communication in the Animal and the Machine, New York: The Technology Press and John Wiley \& Sons, Inc.- Paris: Hermann et Cie, 1948.

[16] Wiener N. Cybernetics or Control and Communication in the Animal and the Machine.- 2nd ed.- New York - London: The M.I.T. Press and John Wiley \& Sons, Inc., 1961

[17] Alexander Klimburg, Philipp Mirtl. Cyberspace and Governance - A Primer. The Austrian Institute for International Affairs, Working Paper 65, September 2012. 
Chulkova.- M.: FGBU DPO 'Educational-methodical center for education in railway transport’, 2016.- 932 pp., Ill.

[29] Chulkov V.O. Anthropotechnics of Infographic Modeling in Management: Modular course of lectures, Vol.4.- Modules 152-154.- M .: Russian School, 2019.pp. 284-317.

[30] Chernyak L. Internet of Things: New Challenges and New Technologies, Open Systems. DBMS, 2013, No. 4.- pp.14-18. URL: http://www.osp.ru/ os / 2013/04/13035551 (reference date: 05.10.2019).

[31] Multilayer Model of a Computer Network, http://iteranet.ru/it-novosti/2014/03/18/mnogoslojnayamodel-vychislitelnoj-seti/ (reference date: 1.07.2019).

[32] Volkov A.A. Cybernetics of Building Systems. Cyber-physical Building Systems, Industrial and civil construction, No. 9, 2017, pp. 4-7.

[33] Health and Safety. Organizational and Anthropotechnical Reliability of Functional Systems of the Mobile Environment of Construction Production.

Series 'Infographic Fundamentals of Functional Systems’, Ed. by V.O. Chulkova, M.: ACB Publishing House, 2003.- 176 p., Ill.

[34] Chulkov V.O., Kazaryan R.R., Levin B.A. Infographic Models of Anthropotechnics of Management: Modular course of lectures. Educational edition in 3 vol, Ed. by V.O. Chulkova. - 1200 p., Ill.

[35] Korotkov D.Yu., Chulkov V.O. Life Cycle of a Construction Project, World of Science, Issue 1, 2013, 7 p.18TMN113

[36] Efimova S.M. On Algebraic Approach to the Problem of Knowledge Representation, Situational control and semiotic modeling: Coll. of inform. materials NS on complex. prob. 'Cybernetics' .- VK-100.- M.: NS on complex. prob. 'Cybernetics' of the Academy of Sciences of the USSR, 1983.- pp. 54-73.

[37] Efimova S.M. S-graphs for Representation of Knowledge. - Messages on Applied Mathematics of the Computing Center of the Academy of Sciences of the USSR. - Res. Editor D.A. Pospelov, M.: Academy of Sciences of the USSR, 1985, $42 \mathrm{p}$.

[38] Codd E.F. Relational Completeness of Data Base Sublanguages. Courant Computer Science Symposia 6, Data Base Systems, New York City, May 24-25, PrinteceYall, 1971

[39] Chulkov V.O., (2019) Modeling of Digitalization of Management in Cyber-physical Systems of Reorganization of Residential Territories.- Advances in Economics, Business and Management Research, volume 105, pp.640-644.- https://doi.org/10.2991/iscde19.2019.124
[28] Levin B.A., Kazaryan R.R., Chulkov V.O. Infographics of Anthropotechnical Management: Scientific publication: in 3 volumes, Ed. by V.O. 